\title{
Métodos radiográficos de localização: contornando as limitações da bidimensionalidade
}

\section{Radiographic methods of localization: bypassing the limitations of the bidimensionality}

Artigo

Original

\author{
Jairo Conde Jogaib ${ }^{1}$ \\ Alcemar Gasparini Netto ${ }^{2}$ \\ Roberta Mansur Caetano ${ }^{3}$ \\ Matheus Figueiredo Mendes $^{4}$
}

Original

Paper

\section{Palavras-chave:}

Radiografia dental;

Dente supranumerário;

Endodontia

\section{Resumo}

O exame radiográfico convencional é o método de diagnóstico por imagem mais utilizado na prática odontológica, porém, fornece uma imagem bidimensional de uma estrutura tridimensional, com ausência da profundidade e ocorrendo sobreposição das imagens radiográficas de estruturas contíguas. O objetivo deste trabalho foi avaliar o conhecimento de 100 cirurgiões-dentistas sobre os métodos radiográficos de localização, utilizando questionário com 10 perguntas, 05 objetivas e 05 subjetivas. Concluímos que o método de Clark é o mais conhecido e utilizado, mas com alta porcentagem de erros em sua interpretação por parte dos entrevistados, mesmo entre os que disseram saber interpretar o método.

\section{Abstract}

The conventional radiographic examination is the method of diagnostic by imaging most used in dental practice, however, it provides a twodimensional image of a three-dimensional structure, with lack of depth and some overlapping of radiographic images of contiguous structures. The aim of this work was to evaluate the knowledge of 100 dentists about the radiographic methods of location using a questionnaire with 10 questions, 05 objective and 05 subjective. We conclude that the Clark's method is the most known and used, but with a high percentage of errors in its interpretation by the interviewees, even among those who said they know how to interpret the method.
Key words:

Dental radiography;

Supernumerary tooth;

Endodontics
Recebido em $\mathbf{0 5} / 2013$

Aprovado em $08 / 2013$

\footnotetext{
1 Doutor em Radiologia; Prof ${ }^{\circ}$ Responsável Disciplinas Imaginologia I e II do Curso de Odontologia do Centro Universitário de Volta Redonda - UniFOA; Vice-Presidente do Centro Universitário de Volta Redonda - UniFOA

2 Especialista em Radiologia e Estomatologia; Mestrando em Ciências da Saúde e Meio Ambiente; Prof $^{0}$ Assistente Disciplinas Imaginologia I e II, Estomatologia e Semiologia do Curso de Odontologia do Centro Universitário de Volta Redonda - UniFOA

3 Doutoranda em Radiologia; Mestre em Radiologia e Imaginologia; Prof ${ }^{\mathrm{a}}$ Assistente Disciplinas Imaginologia I e II do Curso de Odontologia do Centro Universitário de Volta Redonda - UniFOA 


\section{Introdução}

Apesar da existência de métodos de diagnóstico recentes e inovadores, como os sistemas digitais, tomografias computadorizadas e ressonância magnética nuclear, o exame radiográfico convencional é o método de diagnóstico por imagem mais utilizado na prática odontológica. Esse, porém, fornece uma imagem bidimensional de uma estrutura tridimensional, com ausência da profundidade e ocorrendo sobreposição das imagens radiográficas de estruturas contíguas, dificultando a interpretação. Para solucionar esse inconveniente, pesquisadores desenvolveram variadas técnicas de fácil execução, possíveis de serem realizadas no próprio consultório, proporcionando a localização radiográfica de corpos estranhos, tumores, cistos, dentes não irrompidos, reparos anatômicos e dissociação de condutos radiográficos. O objetivo deste trabalho foi avaliar o conhecimento dos cirurgiões-dentistas sobre os métodos radiográficos de localização.

\section{Revisão Bibliográfica}

De acordo com Cruz et al.(2009), a radiografia é o meio mais utilizado e indispensável para o diagnóstico e planejamento, durante e após o tratamento de um caso em Odontologia. No entanto, o exame radiográfico intrabucal apresenta algumas limitações, uma vez que fornece uma imagem bidimensional de uma estrutura tridimensional com sobreposição de estruturas contíguas, por isso, foram criados métodos radiográficos de localização de corpos estranhos, dentes não irrompidos, dentes supra-numerários, tumores, cistos, dissociação de condutos radiculares, entre outros.

Nos consultórios odontológicos, os profissionais podem utilizar procedimentos de localização radiográfica que contribuem para determinar os procedimentos de acesso cirúrgico, como na remoção de caninos superiores não irrompidos, na qual é de grande importância determinar a sua proximidade com as tábuas ósseas vestibular ou palatina. Contribuem também, segundo Gonçalves et al.(2001), na localização de terceiros molares inferiores não irrompidos, elucidando sua relação com o canal mandibular.

Alguns pesquisadores desenvolveram técnicas que posteriormente ficaram conhecidas como métodos radiográficos de localização. Freitas et al.(1994) e Panella (2006) descreveram alguns desses métodos:

- Método de Clark: consiste na realização de duas incidências radiográficas periapicais, modificando apenas a angulação horizontal do feixe de raios $\mathrm{X}$ em uma delas. $\mathrm{O}$ tubo de raios $\mathrm{X}$ se deslocará para mesial ou distal, a estrutura que acompanhar seu deslocamento está localizada por palatina em relação às estruturas vizinhas, e a estrutura que se deslocar no sentido oposto está localizada por vestibular em relação às estruturas vizinhas. Indicado para localização de dentes não irrompidos, corpos estranhos e processos patológicos, reparos anatômicos, dissociação de raízes e condutos radiculares.

- Método de Miller-Winter: utiliza duas tomadas radiográficas, uma periapical e uma oclusal utilizando filme periapical. Indicado para localização de dentes não irrompidos (geralmente o $3^{\circ}$ molar inferior), corpos estranhos, processos patológicos na mandíbula.

- Método de Donovan: é uma modificação ao método de Miller-Winter e também utiliza duas tomadas radiográficas, uma periapical e uma oclusal com filme periapical posicionado sobre o ramo ascendente da mandíbula, com sua borda anterior apoiada sobre a superfície mésio-oclusal do $2^{\circ}$ molar inferior. Indicado para localização de terceiros molares inferiores não irrompidos com retenção transversal no processo alveolar.

- Método de Parma: utiliza uma radiografia periapical com o filme inclinado, com sua borda disto-inferior próxima do assoalho bucal, que deve ser dobrada para não causar desconforto ao paciente. Indicado quando a radiografia periapical convencional não registrar inteiramente o $3^{\circ}$ molar inferior.

- Método de Le Master: utiliza uma radiografia periapical com um rolete de algodão preso a face ativa do filme radiográfico, para melhorar as condições de paralelismo entre os longos eixos do filme e dente e diminuir a angulação vertical da incidência dos raios $\mathrm{X}$, eliminando a sobreposição da imagem do processo zigomático da maxila sobre os ápices 
radiculares dos molares superiores. Indicado para visualização das raízes dos molares superiores sem sobreposição do processo zigomático da maxila.

\section{Metodologia}

Foi realizada uma pesquisa de campo com cem cirurgiões-dentistas, recém-formados ou experientes, especialistas ou não, que consentiram que os dados colhidos por meio de um questionário, pudessem ser utilizados no trabalho para verificar seus conhecimentos sobre os métodos radiográficos de localização. O questionário constou de 10 perguntas, 05 objetivas e 05 subjetivas. Os cirurgiões-dentistas foram escolhidos aleatoriamente e não foram levadas em consideração a idade, naturalidade, faculdade em que concluiu a graduação.

\section{Resultados e Discussão Teórica}

Dos cem cirurgiões-dentistas que responderam aos questionários, $22 \%$ eram clínicos gerais e $78 \%$ especialistas - em ortodontia $(12 \%)$, endodontia $(12 \%)$, prótese $(5 \%)$, periodontia (5\%), cirurgia bucomaxilofacial (4\%), odontopediatria (4\%), implantodontia $(4 \%)$, dentística (3\%), \%), patologia bucal $(1 \%)$, mais de uma especialidade (26\%) (Gráfico 1). Desses, 15\% apresentavam menos de 5 anos de formados, $18 \%$ entre 5 e 10 anos, $16 \%$ entre 10 e 15 anos, $15 \%$ entre 15 e 20 anos, $11 \%$ entre 20 e 25 anos, $13 \%$ entre 25 e 30 anos e $12 \%$ mais de 30 anos.

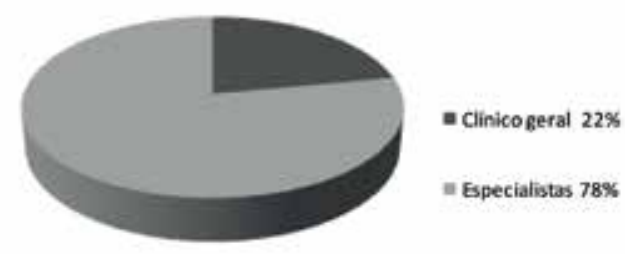

Gráfico 1 - Distribuição dos entrevistados
Apenas dois métodos radiográficos de localização foram citados pelos entrevistados, Clark e Le Master, 51\% e 4\% respectivamente, quando foi possível perceber desconhecimento dos entrevistados, que citaram várias técnicas radiográficas intra-orais e extra-orais e não métodos radiográficos de localização. $\mathrm{O}$ mesmo aconteceu quando foi perguntado qual o método os profissionais entrevistados mais empregam e $43 \%$ responderam o método de Clark, também citando várias técnicas radiográficas intra-orais e extra-orais e não métodos radiográficos de localização. É possível que, na clínica diária, vários métodos sejam empregados sem que os profissionais os associem a seus respectivos nomes.

Apesar de 84\% dos entrevistados possuírem aparelho de raios $\mathrm{X}$ no consultório, quando necessitam utilizar métodos radiográficos de localização, $41 \%$ realizam no próprio consultório, $47 \%$ solicitam de clínicas de radiologia e $12 \%$ realizam no consultório e/ou solicitam de clínicas de radiologia. Essa alta porcentagem de exames solicitados às clínicas de radiologia pode ser explicada pela dificuldade de interpretação radiográfica.

Quando foi perguntado para qual especialidade odontológica julgava mais importante a utilização dos métodos radiográficos de localização, 35\% desses profissionais responderam para todas as especialidades, sendo algumas mais citadas, como a cirurgia, endodontia, ortodontia e implantodontia.

O método de Clark é o mais conhecido entre todos os métodos para localização de estruturas. $85 \%$ dos entrevistados responderam saber interpretar esse método (Gráfico 2), mas, por meio de uma situação clínica apresentada no questionário, verificamos que apenas 51\% responderam corretamente e $49 \%$ erraram ou não souberam responder (Gráfico 3). Cruz et al.(2009) também encontraram alta porcentagem de erros de interpretação dessa técnica, $44 \%$ dos clínicos gerais e $26 \%$ dos especialistas. Isso nos leva a concluir que os profissionais possam estar cometendo erros em procedimentos odontológicos, em função de uma interpretação errônea do recurso radiográfico. 


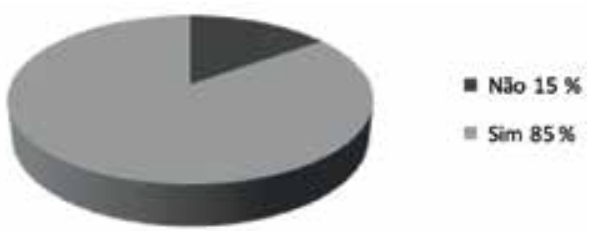

Gráfico 2 - Pergunta: Sabe interpretar o método de Clark?

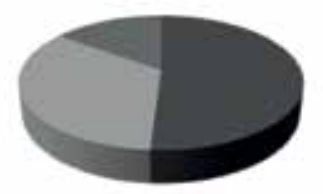

Gráfico 3 - Interpretação do método de Clark através de caso apresentado

\section{Conclusões}

Podemos concluir que o método radiográfico de localização mais conhecido é o de Clark, mas com alta porcentagem de erros em sua interpretação, mesmo entre os profissionais que dizem saber interpretar o método, deixando assim margem para erros durante os procedimentos odontológicos em que esse se faça necessário.

\section{Referências Bibliográficas}

1. BOTTICELLI, S. et al. Two versus three dimensional imaging in subjects with unerupted maxillary canines. European Journal of Orthodontics, v.33, p. 344349, 2011.

2. CRUZ, L.P. et al. Grau de conhecimento dos cirurgiões-dentistas sobre os métodos radiográficos de localização. $R G O$, Porto Alegre, v.57, n.3, p.269-272, jul/set. 2009.

3. DENARDI, C.A.S. Estudo sobre os métodos de localização radiográfica. Piracicaba, 2002.

4. FREITAS, A.; ROSA, J.E.; SOUZA, I.F. Radiologia Odontológica. $3^{\mathrm{a}}$ edição, Porto Alegre, Artes Médicas, 1994. 680p.

5. GONÇALVES, M. et al. Avaliação de métodos de localização radiográfica para o clínico geral - parte II. Revista da Faculdade de Odontologia, Passo Fundo, v.6, n.1, p.53-57, jan./jun. 2001.

6. PANELLA, J. Fundamentos de Odontologia. Radiologia Odontológica e Imaginologia. $1^{\text {a }}$ edição, Rio de Janeiro, Guanabara Koogan, 2006. 358p.

7. SETTANNI, C.E.P. Estudo comparativo das Técnicas radiográficas de Clark e de Keur com a tomografia linear no diagnóstico topográfico do dente canino superior impactado. $J$ Bras Ortodon Ortop Facial, v. 9, n.51, p. 235-41, 2004.

8. SILVA, D.N. et al. Métodos radiográficos no diagnóstico de quartos molares mandibulares. RFO, Porto Alegre, v.12, n.2, p.79-83, maio/agosto 2007. 